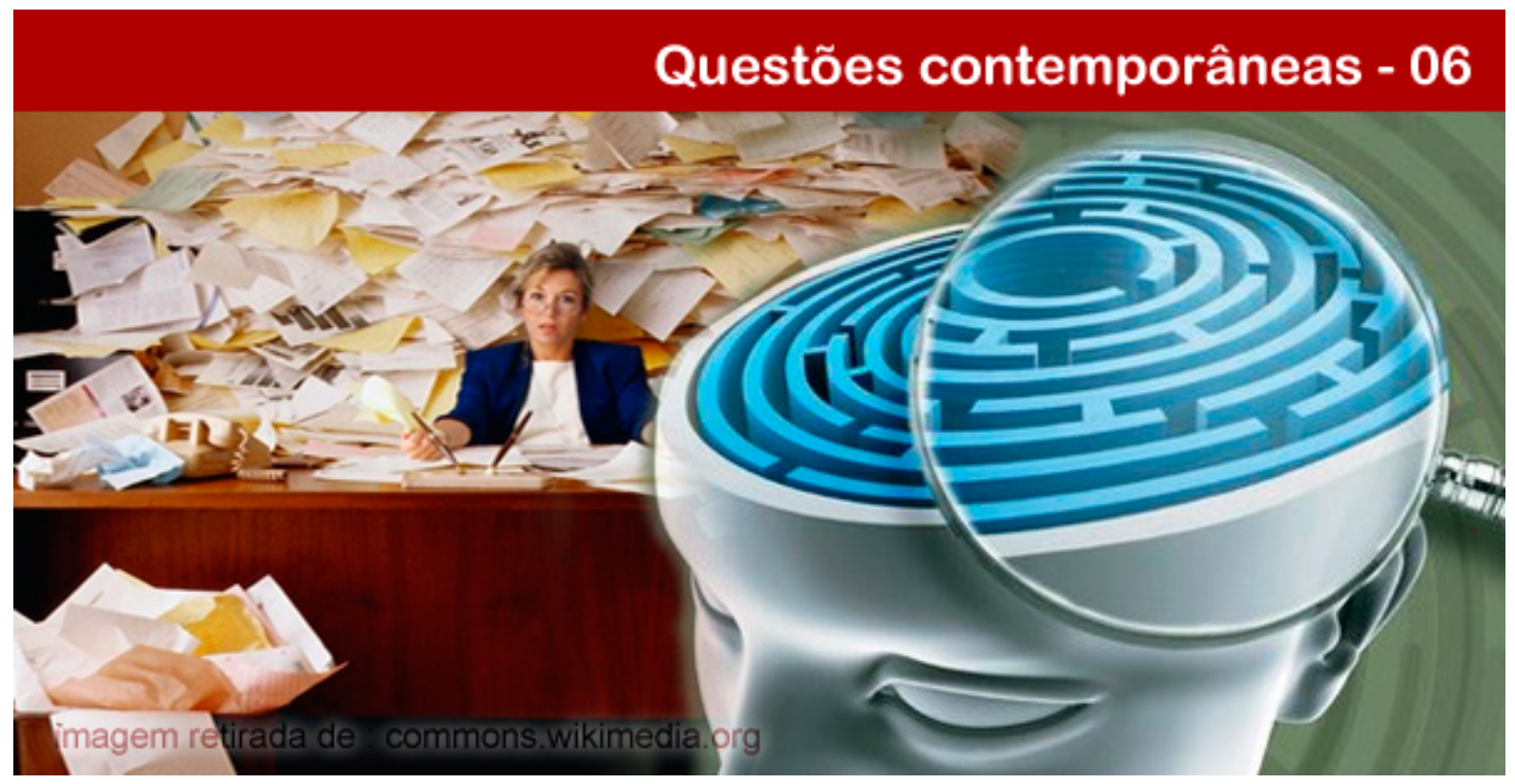

\title{
SAÚDE MENTAL E TRABALHO: UMA REFLEXÃO SOBRE A POSSÍVEL RELAÇÃO ENTRE O DIAGNÓSTICO E AS SITUAÇÕES DE TRABALHO
}

\section{Cristiane Girotto}

Psicóloga pelo Centro Universitário UNIVATES. E-mail: kcrystyane@gmail.com.

\section{Liciane Diehl}

Doutoranda em Psicologia pela UNISINOS. Mestre em Psicologia Social pela PUC-RS. Especialista em Gestão Estratégica de Pessoas pela UNIVATES. Psicóloga pela UNISINOS. Professora e Coordenadora do Curso de Gestão de Recursos Humanos da UNIVATES.

Resumo: O estabelecimento do nexo causal entre o trabalho e o adoecimento é um tema complexo, já que cada processo é único e envolve a história de vida e de trabalho de cada sujeito. Este estudo trata de uma pesquisa qualitativa de cunho exploratório e descritivo, que se utilizou de um estudo de caso único para investigar e analisar a possível relação entre o diagnóstico e as situações de trabalho de uma trabalhadora afastada de suas atividades laborais por adoecimento mental. Os dados foram coletados por meio de entrevistas semiestruturadas e analisados pela técnica de análise de conteúdo, conforme Bardin (1977). Os resultados indicam que a sobrecarga de trabalho, o modo de gestão e a falta de apoio da empresa contribuíram para o seu adoecimento. Ainda, o apoio social, medicamentos e psicoterapia influenciaram na sua recuperação. É possível constatar que as situações de trabalho contribuíram para o adoecimento mental da entrevistada. Espera-se que o resultado desta pesquisa contribua para a problematização e o debate deste tema, ampliando, também, o conhecimento sobre o assunto.

Palavras-chave: Saúde do trabalhador. Nexo causal. Adoecimento mental.

\section{MENTAL HEALTH AND WORK: A REFLECTION ON POSSIBLE RELATIONSHIP BETWEEN THE DIAGNOSIS AND WORKING CONDITIONS}

Abstract: Establishing the causal relationship between work and illness is a complex issue, as each case is unique and involves the history of life and of each individual work. This study is a qualitative exploratory and descriptive nature survey, which used a single case study to investigate and analyze the possible relationship between diagnosis and work situations of a working away from their work activities for mental illness. Data were collected through semi-structured interviews and analyzed by content analysis technique, according to Bardin (1977). The results indicate that the workload, the mode of administration and the lack of firm support

\section{POLÊM!CA | LABORE (}

Polêmica - Revista Eletrônica da Uerj - Rua São Francisco Xavier, 524, $1^{\circ}$ andar

bloco D, sl.1001 • Tels.: +55 21 2334-4088 / 4087 • http://www.e-publicacoes.uerj.br/index.php/polemica/index http://www.labore.uerj.br • laboreuerj@yahoo.com.br 
contributed to their illness. Still, social support, medication and psychotherapy influenced in their recovery. It is established that the work situations contributed to the mental illness of the interviewee. It is expected that the results of this research contribute to the questioning and discussion of this topic, expanding also the knowledge on the subject.

Keywords: Occupational health. Causal link. Mental illness.

\section{Introdução}

No Brasil, os assuntos relacionados à saúde do trabalhador foram exclusivos do Ministério do Trabalho desde sua concepção, em 1934, até momentos antes da divulgação da Constituição de 1988, quando foram divididos entre os Ministérios da Saúde e Previdência Social. O vínculo destes com o Ministério do Trabalho consentiu a assinatura, no ano de 1943, da Consolidação das Leis Trabalhistas (CLT), que versou sobre a garantia de Segurança e Medicina do Trabalho (MENEZES-VASQUES, 2012).

A autora discute que, se por um lado, essa vinculação favoreceu o avanço da relação trabalho-saúde-trabalhador, especialmente no que se refere ao caráter normativo e fiscalizador, por outro lado, afastou ainda mais as ações relacionadas à saúde física do trabalhador e aos fatores subjetivos da relação saúde-doença-sofrimento psíquico. MinayoGomez e Thedim-Costa (1997) advertem que a Medicina do Trabalho sempre atuou na forma tradicional de considerar o trabalhador a partir de uma visão eminentemente biológica e individual, orientada pela teoria da unicausalidade, agindo sobre as consequências e medicalizando sintomas.

Visando o modelo teórico da Saúde do Trabalhador, o que o distingue é a participação do sujeito como indivíduo ativo no processo saúde-doença (agregando ações efetivas de saúde) e não apenas como elemento da atenção à saúde, diferente do que é adotado pela Medicina do Trabalho e a Saúde Ocupacional. Trata-se de uma constituição de práticas diferenciadas das ações centradas no conhecimento médico e nos saberes divididos em compartimentos, como Engenharia, Psicologia, Medicina, Enfermagem e Serviço Social. A Saúde do Trabalhador aborda uma prática voltada para a interdisciplinaridade, com equipe multiprofissional sem brechas, como acontece na Medicina do Trabalho e na Saúde Ocupacional, respectivamente (NARDI, 2000).

A inclusão da Psicologia na área da Saúde do Trabalhador difundiu uma gama de possibilidades de atuação do profissional desta área, sendo uma delas o nexo causal entre o adoecimento mental e o trabalho. Tais possibilidades de atuação implicam na maior compreensão do ser humano em suas várias extensões (JACQUES, 2007).

\section{POLÊM!CA | LABORẸ}

Polêmica - Revista Eletrônica da Uerj - Rua São Francisco Xavier, 524, $1^{\circ}$ andar

bloco D, sl.1001 • Tels.: +55 21 2334-4088/4087 • http://www.e-publicacoes.uerj.br/index.php/polemica/index

http://www.labore.uerj.br • laboreuerj@yahoo.com.br 
O estabelecimento do nexo causal entre o trabalho e o adoecimento tem sido amplamente discutido, apresentando-se como um tema complexo, já que cada processo é único e envolve a história de vida e de trabalho de cada sujeito. Segundo Glina et al. (2001), para estabelecer o nexo, é fundamental que se descreva detalhadamente a situação de trabalho quanto ao ambiente, à organização e à percepção da influência do trabalho no processo de adoecer. Carlotto (2010) acrescenta que uma investigação dessa natureza deve contemplar técnicas, como entrevistas, testes psicológicos e questionários, observações do contexto do trabalho e consultas a estudos epidemiológicos.

Lima (2006), por sua vez, infere que uma investigação diagnóstica no campo da saúde do trabalhador deve seguir as seguintes etapas: $1^{\circ}$ ) Buscar evidências epidemiológicas a fim de identificar possíveis focos de problemas; $2^{\circ}$ ) Dirigir-se aos locais onde esses profissionais se encontram e realizar estudos ergonômicos e das atividades reais de trabalho; $3^{\circ}$ ) Resgatar a história de vida desses profissionais da forma mais detalhada possível e verificando a percepção que eles próprios sustentam sobre as causas do seu adoecimento; $4^{\circ}$ ) Complementar tais informações com exames médicos e psicológicos, além de dados coletados junto às entidades de classe e outros que possam auxiliar na compreensão do problema; 5º Identificar os mediadores que permitam compreender concretamente como se dá a passagem entre a experiência vivida pelos sujeitos e o seu adoecimento, principalmente durante a segunda e a terceira etapas previamente descritas.

Conforme Jacques (2007), há um encobrimento do sujeito quanto ao seu sofrimento, no que concerne à necessidade de enquadrar o sintoma em uma classificação psicopatológica. Isto acaba por alienar o indivíduo no seu processo de adoecimento. Para a autora, estabelecer o nexo causal entre a atividade do trabalhador e a doença é o ponto inicial para um diagnóstico e terapia adequados, também para registro de informações e ações voltadas à vigilância.

Com base na abordagem do nexo causal em saúde/doença mental no trabalho, esta pesquisa propôs investigar e analisar a possível relação entre um diagnóstico e as situações de trabalho. Para tanto, foi utilizado, como estratégia de investigação, o relato de uma trabalhadora afastada por diagnóstico de doença mental. Trata-se, portanto, de uma pesquisa qualitativa de cunho exploratório e descritivo.

Salienta-se que esta pesquisa não tem como finalidade defender, por meio do estudo

\section{POLÊM!CA $\mid$ LABORE}


de caso único, o nexo causal, pois, tomando como base as propostas de investigação diagnóstica indicadas pelos autores, este estudo contemplou apenas o resgate da história de vida da profissional, verificando a sua própria percepção acerca das causas do seu adoecimento. Logo, aqui se pretende promover a reflexão acerca do tema e ampliar a discussão sobre possíveis relações entre o sofrimento e o adoecimento relacionados ao trabalho, utilizando, para isso, os pressupostos teóricos do nexo causal.

Assim, inicialmente apresenta-se um constructo referente ao tema, de cunho teórico. Em seguida, abordam-se os procedimentos metodológicos atinentes à pesquisa e os resultados articulados teoricamente, subsidiando as relações de análise. Finalmente, apresentam-se as considerações finais, retomando o processo de análise e as referências utilizadas.

\section{A Saúde do Trabalhador e a Psicologia do Trabalho}

Lacaz (2007) alega que a Saúde do Trabalhador emerge, no Brasil, como enfoque teórico-metodológico da Saúde Coletiva. Surge um novo foco em meio a uma sociedade que vive várias mudanças econômicas, políticas e sociais. Este enfoque busca, através do operário industrial, estabelecer conhecimentos e intervenções sobre saúde-doença nas relações de trabalho. Esse campo em construção unifica-se devido à referência e identificação com a Saúde Ocupacional, ao qual esta congrega:

[...] práticas e conhecimentos da clínica, medicina preventiva e epidemiologia clássica, mediante a história natural da doença para a análise das doenças e acidentes do trabalho mediante a tríade "agente-hospedeiro-ambiente", conforme proposto em 1950 pelo Comitê Misto de Peritos da Organização Internacional do Trabalho (OIT)/Organização Mundial da Saúde (OMS) (LACAZ, 2007, p. 758).

Conforme Nardi (2000), a saúde do trabalhador é entendida a partir do conjunto de subsídios provenientes de diversas áreas (Saúde Coletiva, Psicologia, Medicina do Trabalho, Saúde Pública, Epidemiologia Social, entre outras). Complementa o autor que, em conjunto com o saber advindo do trabalhador sobre suas práticas - experiências das situações vividas no seu ambiente de trabalho, articuladas sob uma perspectiva nova de concepção acerca das relações saúde e trabalho - propõe-se uma prática diferenciada na atenção voltada à saúde dos trabalhadores em seus ambientes de trabalho.

A Lei Orgânica da Saúde, 8080/90, no Art. $6^{\circ}$, inciso $3^{\circ}$, define a saúde do trabalhador como:

\section{POLÊM!CA $\mid$ LABORE}


[...] um conjunto de atividades que se destina, através das ações de vigilância epidemiológica e vigilância sanitária, à promoção e proteção da saúde dos trabalhadores, assim como visa à recuperação e reabilitação da saúde dos trabalhadores submetidos aos riscos e agravos advindos das condições de trabalho [...] (MINISTÉRIO DA SAÚDE, 1990).

A $3^{\text {a }}$ Conferência Nacional de Saúde do Trabalhador configura a "Saúde do Trabalhador” como algo ligado inteiramente à saúde, compreendida como parte e responsabilidade do SUS que, devido à área de ação de seu campo, é caracterizada como:

[...] intra-setorial (envolvendo todos os níveis de atenção e esferas de governo do SUS) e inter-setorial (envolvendo setores relacionados com a Previdência Social, Trabalho, Meio Ambiente, Justiça, Educação e demais setores relacionados com as políticas de desenvolvimento), exigindo uma abordagem multiprofissional e interdisciplinar (saúde, engenharia, ciências humanas) e com a participação pró-ativa do trabalhador (MINISTÉRIO DA SAÚDE, 2005, p. 4).

Minayo-Gomez e Thedim-Costa (1997, p. 25) entendem por Saúde do Trabalhador um conjunto de "práticas teóricas interdisciplinares - técnicas, sociais, humanas - e interinstitucionais, desenvolvidas por diversos atores situados em lugares sociais distintos e informados por uma perspectiva comum”. Segundo Lacaz (2007, p. 760), o enfoque em Saúde do Trabalhador, “[...] busca resgatar o lado humano do trabalho e sua capacidade protetora de agravos à saúde dos trabalhadores, tais como mal-estares, incômodos, desgastes, para além dos acidentes e doenças”.

Desta forma, na medida em que a saúde do trabalhador solicita formas de atuação que adotem não apenas um olhar aos aspectos biológicos, mas que também incorpore os fatores psíquicos e sociais, a Psicologia inicia a sua aproximação com os problemas de saúde do trabalhador (SATO, LACAZ, BERNARDO, 2006). No Brasil, um marco importante para a inserção da Psicologia na pauta da saúde do trabalhador foi a criação da Rede Nacional de Atenção Integral à Saúde do Trabalhador (RENAST) em 2002, cuja finalidade foi a de articular ações de saúde do trabalhador por meio de ações assistenciais, de vigilância, prevenção e de promoção da saúde (CARLOTTO, MICHELETO, 2014).

A abordagem da psicologia do trabalho, por sua vez, é de difícil análise, considerando a sua vasta amplitude. Bendassolli (2011) afirma que, nesta linha da psicologia, o trabalho não é reduzido ao emprego, mas corresponde a uma atividade, de modo que, nessas abordagens, tendem a predominar a concepção do sujeito psíquico e uma visão nominalista de ciência e da realidade. A descrição que melhor define essa linha é a ligação entre a vida psíquica e o

\section{POLÊM!CA $\mid$ LABORE}

Polêmica - Revista Eletrônica da Uerj - Rua São Francisco Xavier, 524, $1^{\circ}$ andar

bloco D, sl.1001 • Tels.: +55 21 2334-4088/4087 • http://www.e-publicacoes.uerj.br/index.php/polemica/index http://www.labore.uerj.br • laboreuerj@yahoo.com.br 
trabalho. O autor defende o trabalho como ponto principal da disposição das ações psíquicas primordiais do sujeito e estaria em domínio da ação, sendo que haveria uma ligação estreito entre consciência e ação estabelecida. A produtividade e a eficiência não estariam sob um olhar exclusivo, e sim a evolução do conhecimento individual com o trabalho, seja ele na obtenção da satisfação, ou sobre o poder de ação coletiva e individual.

Codo, Soratto e Vasques-Menezes (2009) afirmam que o significado de psicologia do trabalho que se está assumindo é de origem, ou seja, de causa, isto é, uma parte dos significados dos fenômenos que a psicologia estuda vem da sua origem, sua consignação - é esclarecida no e pelo trabalho. Segundo os autores, para compreender a psicologia, é preciso compreender o trabalho e que ele é um instrumento necessário para se entender o fenômeno psicológico, tal como, por exemplo, a psicanálise afirmou que seria necessário compreender a sexualidade para entender a força psicológica.

Desta forma, os autores entendem como psicologia do trabalho, o exercício capaz de nos auxiliar a entender o ser humano, encargo este da própria psicologia. Ou, possivelmente, mais do que isso. Essa seria a verdadeira definição de psicologia do trabalho, porque sem o trabalho seria impraticável o fazer psicologia. O trabalho tem um papel importante na vida do sujeito, já que às vezes pode se configurar de forma negativa, abarcando prejuízos psicológicos e sociais, afetando a saúde dos sujeitos.

De acordo com Leão (2012), uma particularidade da psicologia do trabalho é a pluralidade e multiplicidade de orientações teórico-metodológicas, de modo que se torna difícil afirmar que existe coesão conceitual e prática demarcadora de propostas de investigação e ação. Trata-se de uma área heterogênea, que abrange diferentes abordagens teórico-metodológicas e propostas técnico-operacionais.

Atualmente existem diversos ramos de interface entre trabalho e saúde mental: clínicas do trabalho, enfoques de estresse, assédios e violências psicológicas; linhagens da psicopatologia do trabalho e da psiquiatria, incluindo a vertente do desgaste mental; psicossociologia e análises institucionais; e abordagens organizacionais e da subjetividade (DA COSTA LEÃO, GOMEZ, 2014). Além disso, a atuação do psicólogo pode se dar em diferentes contextos, como em equipes de saúde pública, em espaços institucionais, como escolas, hospitais, organizações empresariais, sindicatos, e também na clínica privada (JACQUES, 2007).

\section{POLÊM!CA $\mid$ LABORE}


No entanto, independentemente do ramo de interface entre trabalho e saúde mental e do contexto em que está inserido, é fundamental, como refere Jacques (2007), que o psicólogo tenha o instrumental teórico e metodológico que lhe permita estabelecer o nexo causal entre o trabalho e o adoecimento mental em acordo com as regras da legislação brasileira. Apesar de o Brasil sustentar um cenário de crescimento de estatísticas de doenças mentais relacionadas ao trabalho (AMAZARRAY, CÂMARA, CARLOTTO, 2014), os distúrbios psíquicos relacionados ao trabalho frequentemente não são reconhecidos como tais no momento da avaliação clínica, o que pode estar relacionado às próprias características dos transtornos, mascarados por sintomas físicos (GLINA, ROCHA, BATISTA, MENDONÇA, 2001). Neste contexto, evidencia-se a importância do estabelecimento do nexo causal.

\section{$\underline{\text { Nexo Causal }}$}

Para se obter um conhecimento preciso em saúde mental e trabalho, é necessário pesquisar a importância que o trabalho tem para o indivíduo e a importância que este compreende o trabalho em âmbito social (CODO, 2007). O tema nexo causal voltou a ser discutido com a medida provisória de número 316, em 11 de agosto de 2006, exibida pelo governo federal, a qual dispõe o nexo técnico epidemiológico (MINISTÉRIO DA PREVIDÊNCIA E ASSISTÊNCIA SOCIAL, 2006). A medida estabelece a inversão do ônus de prova em determinados casos, quando é produzido o registro automático da doença como sendo relacionada ao trabalho.

Os discursos acometidos na Previdência, sobre a adoção do Nexo Técnico Epidemiológico Previdenciário (Ntep), e em fóruns científicos e demais, contribuem com a propagação da nova forma de registrar as doenças e acidentes relacionados ao trabalho. Essa experiência necessita ser estudada buscando metodologias consolidadas cientificamente. O objetivo da Previdência Social ao criar a Diretoria de Políticas de Saúde e Segurança do Trabalho é o de intensificar a prevenção. E, para isso, é de fundamental importância o conhecimento amplo e preciso sobre o adoecimento no trabalho, e sobre a epidemiologia através do Nexo Técnico Epidemiológico (TODESCHINI; LINO, 2010).

A averiguação do nexo causal juntamente com o trabalho abona ao trabalhador garantias que lhes são de direito. Elas são previstas pela legislação, abarcando garantia econômica e de estabilidade de emprego, pelo tempo de um ano após seu retorno. Em certos

\section{POLÊM!CA $\mid$ LABORE}


casos, colabora acerca da diminuição da "responsabilização do trabalhador pelo acidente ou pelo adoecimento e as consequências daí derivadas associadas à culpa imputada por outros ou à própria auto-culpabilização” (JACQUES, 2007, p. 117).

A autora defende que há uma gama de fatores que contribuem para a alteração da saúde mental relacionada ao trabalho, sejam eles pontuais - como a exposição a agentes tóxicos -, até a complexa articulação de fatores relativos à organização do trabalho. E acrescenta:

As teorias divergem sobre o papel do trabalho no processo de adoecimento mental, considerando-o ou como determinante ou como fator desencadeante a partir de uma estrutura pré-existente. Além disso, os transtornos mentais têm uma etiologia multicausal em que conjuntos de diversos fatores interagem de modo complexo (JACQUES, 2007, p. 115).

Tais fatores contribuem para as dificuldades para o estabelecimento do nexo causal. No mesmo sentido, Lima (2005) refere que quadros depressivos de fadiga nervosa, síndrome do pânico, transtornos relacionados ao alcoolismo, estados de estresse pós-traumático, transtornos orgânicos de personalidade, dentre outros, têm se mostrado como quadros que se encaixam vezes sim, vezes não, nas classificações nosológicas comumente descritas nos manuais de psiquiatria.

Moura Neto (2014) acrescenta que o estabelecimento da relação causal entre agravos à saúde mental e o trabalho tem gerado questionamentos e conflitos entre técnicos vinculados ao Sistema Único de Saúde (SUS) e aos departamentos de saúde dos sindicatos de trabalhadores com peritos do Instituto Nacional de Seguridade Social (INSS) e técnicos dos serviços de Segurança e Medicina do Trabalho das empresas. Os profissionais que sustentam a impossibilidade do estabelecimento desse nexo servem-se de argumentos que desqualificam a objetividade dos complexos sintomas psíquicos, apontando para aquilo que aparenta ser o aspecto mais contraditório da relação entre saúde mental e trabalho: a invisibilidade das cargas de trabalho psíquicas.

Minayo (2007) sintetiza que os efeitos de saúde e doença influem tanto no corpo como em repercussões no imaginário: ambas implicações são reais. Assim, as ações clínicas, técnicas, de tratamento, de prevenção ou de planejamento precisam estar atentas aos valores, atitudes e crenças das pessoas envolvidas. A autora acrescenta que a inclusão dos âmbitos conceituais abrangendo o subjetivo e o social como elementos indispensáveis não diminui a

\section{POLÊM!CA $\mid$ LABORE}


cientificidade da saúde; pelo contrário, complementam-se dando maior visibilidade aos fenômenos que os envolvem.

Ainda que não tenha sido foco da presente pesquisa estabelecer o nexo causal entre saúde/doença mental e trabalho, conhecer os aspectos que envolvem essa dinâmica contribui para aprimorar o entendimento das relações entre o trabalho e o indivíduo. O trabalho não é apenas um meio de subsistência, mas constituidor de identidade, podendo ser fonte de saúde ou de doença. Desta forma, emerge a necessidade de uma nova mentalidade que permita a reflexão sobre riscos e a prática investigativa e compreensiva do psicólogo do trabalho em prol da saúde do trabalhador.

\section{Procedimentos Metodológicos}

Trata-se de uma pesquisa de cunho exploratório e descritivo, com abordagem qualitativa. A pesquisa de cunho exploratório consente ao pesquisador abranger sua experiência em determinado problema. Já o estudo descritivo visa à precisão da descoberta, a frequência dos fenômenos, a conexão e relação aos restantes, sua natureza e características (TOMASI, YAMAMOTO, 1999). A pesquisa seguiu abordagem qualitativa, pois voltou-se para a busca do significado das coisas, ou seja, sobre o que as “coisas” (fenômenos, manifestações, ocorrências, fatos, eventos, vivências, ideias, sentimentos, assuntos) representam para a vida das pessoas (TURATO, 2005).

Estudou-se o caso de uma trabalhadora de 27 anos de idade, que exerce o cargo de Assistente Administrativa, possui nível superior completo e que consentiu em participar de um projeto intitulado "Saúde mental e trabalho: uma reflexão sobre a possível relação entre o diagnóstico e as situações de trabalho”, o qual foi constituinte do trabalho de conclusão do curso de Psicologia de uma das autoras. O estudo de caso único investiga um fenômeno contemporâneo dentro de seu contexto da vida real, enfrentando uma situação tecnicamente única em que haverá muito mais variáveis de interesse do que pontos de dados (YIN, 2015).

Como critério de inclusão, estava estabelecido que o participante do estudo tivesse história de afastamento laboral por motivo de adoecimento mental e que a licença saúde fosse superior ao tempo de cem dias. A inserção da orientadora do trabalho em um grupo voluntário de Recursos Humanos (RH) composto por 32 empresas de pequeno, médio e grande portes, existente há dez anos, facilitou a aproximação com potenciais candidatos a participarem do

\section{POLÊM!CA $\mid$ LABORE}


estudo. O processo de seleção foi iniciado a partir de contatos telefônicos com profissionais responsáveis pelas áreas de RH dessas organizações, quando foi explicado o objetivo da pesquisa e esclarecido o compromisso de sigilo. Embora tenha se percebido inicial resistência, considerando que o tema é polêmico e pode colocar em evidência desajustes do contexto de trabalho das empresas em questão, houve indicação de candidatos, de modo que nomes de três trabalhadores com histórico de adoecimento mental com possível relação com o trabalho foram sugeridos. A escolha final ocorreu pelo preenchimento do critério de inclusão referente à licença saúde ser superior a cem dias e pela acessibilidade.

A partir do conhecimento prévio de onde a trabalhadora estava atuando profissionalmente, o primeiro contato ocorreu por telefone, momento em que foi informado o objetivo de estudo e agendado um encontro pessoal que oportunizasse a elucidação dos propósitos da pesquisa. Na ocasião do primeiro encontro, foi lido e assinado o Termo de Consentimento Livre e Esclarecido. Em seguida, foi agendada a primeira entrevista para a investigação de informações por meio das seguintes questões norteadoras: trajetória profissional, descrição atual de vida e de trabalho, importância do trabalho, modo como aconteceu o afastamento, quais sintomas sentiu, como enfrentou a situação, apoios recebidos.

Foram realizadas duas entrevistas em local privativo, em horário de interesse da entrevistada, totalizando o tempo de uma hora e dez minutos. As entrevistas foram gravadas e posteriormente transcritas, seguindo fielmente a fala da participante. Utilizou-se o método de análise de conteúdo citado por Bardin (1977) como a análise das comunicações, que tem como proposta obter, por meio de métodos sistemáticos e objetivos, a captação do conteúdo das mensagens, permitindo a inferência de conhecimentos. Os dados foram organizados em categorias de acordo com as questões norteadoras da entrevista semiestruturada somadas às novas informações que espontaneamente surgiram ao longo da entrevista. Assim, estabeleceram-se as seguintes categorias: Significado do trabalho; Possíveis fatores de adoecimento; Dos sintomas para a doença/diagnóstico; Autoculpabilização; Fatores contribuintes para a recuperação. Bardin (1977) aborda que as categorias são uma maneira resumida de pensamento que reflete a realidade em determinados momentos.

\section{Resultados e Discussão}

Camila (nome fictício) tem 27 anos, recentemente graduada em Administração de

\section{POLÊM!CA $\mid$ LABORE}


Empresas, tem namorado e atualmente mora com sua mãe. Seu pai faleceu de câncer quando tinha dez anos de idade. Tem sete irmãos e é uma das mais novas da família, sendo seus irmãos todos casados.

Camila é natural de uma cidade do interior do Rio Grande do Sul (RS). Deu início à vida profissional aos 14 anos de idade, sendo que seu primeiro emprego foi no comércio. Trabalha como Assistente Administrativa há seis anos em uma organização de grande porte, do ramo de prestação de serviços da região da qual é natural. A participante está atuando no setor atual há cinco meses, depois de um afastamento de 60 dias, que foi renovado por pedido da médica por mais 60 dias decorrente de um diagnóstico de Transtorno de Ansiedade Generalizada (TAG). Camila havia trabalhado em três setores diferentes nessa mesma organização e, após passar para o quarto setor, acabou desenvolvendo o quadro. A participante não teve nenhum outro tipo de afastamento anterior decorrente do trabalho.

\section{$\underline{\text { Significado do Trabalho }}$}

As falas da participante do estudo em relação ao significado do trabalho em sua vida, além de adotar o caráter de sustento material, remetem a concepções como fonte de identificação e autoestima, além de viabilizar o uso de suas potencialidades:

Pra mim o trabalho sempre foi uma possibilidade assim de... assim de... me destacar como pessoa e... com certeza para auxiliar também nos recursos financeiros né, pra gente se manter. [...] E eu me considero super comunicativa, então eu consegui um trabalho, assim, logo na minha área, que eu gostava de me comunicar.

O significado e o valor do trabalho dependem das crenças e das atitudes que as pessoas têm em relação a ele (BENDASSOLLI, 2009). Ribeiro e Léda (2004) entendem que é importante que o trabalho esteja integrado à vida do sujeito, ter um sentido, não se restringindo a ser um meio de sobrevivência. O indivíduo precisa vislumbrar a possibilidade de realização dos seus planos e projetos, desvinculados do mero acesso a bens materiais e suas simbologias.

As reflexões da entrevistada vão ao encontro de Navarro e Padilha (2007) ao afirmarem que o trabalho não está apenas articulado com a satisfação de necessidades básicas, mas é também uma fonte de identificação e autoestima, de ampliação de potencialidades e de pertencimento à sociedade. Para esses autores, o trabalho significa, ainda, uma senha de identidade.

\section{POLÊM!CA $\mid$ LABORE}


O depoimento de Camila ainda indica que o ambiente de trabalho deve ser um local que propicie bem-estar, ficando evidente que, além do espaço físico, a equipe e as relações de trabalho afetam esse meio:

\begin{abstract}
Penso que o trabalho hoje é um lugar que a gente tem que tá desenvolvendo atividades que a gente se sinta bem, que a gente se sinta realizada, que a gente possa levantar de manhã e... saber que tá indo fazer coisas boas, coisas que a gente gosta, gosta de estar com pessoas que são importantes pra gente, né? Que possam nos ajudar e a gente ajudar as outras pessoas também.
\end{abstract}

É nessa relação que o sujeito se reconhece em um processo de investigação de similaridades e de diferenças. O cotidiano ajuda na constituição da identidade individual e social. É a partir de trocas materiais e afetivas que o sujeito constitui sua singularidade em meio às diferenças. O espaço do trabalho é um campo importante para essas trocas, aparecendo como um mediador do desenvolvimento, da constituição e da complementação da identidade e da construção da vida psíquica (LANCMAN, 2008).

O trabalho envolve os interesses e os desejos individuais do trabalhador articulados aos institucionais. Por isso as instituições precisam buscar estratégias que propiciem prazer no trabalho, promovendo ações de escuta e trocas que repercutam na constituição de um ambiente de trabalho com um clima favorável e de saúde mental do trabalhador (GLANZNER, OLSCHOWSKY, KANTORSKI, 2011).

\title{
$\underline{\text { Possíveis fatores de adoecimento }}$
}

O relato de Camila retrata auto percepções relacionadas à sobrecarga de trabalho. Menezes de Carvalho e Dutra de Moraes (2011) referem que a sobrecarga é decorrente de uma carga de trabalho que excede a capacidade dos sujeitos. Está relacionada à intensificação de trabalho atrelada à ideologia da excelência e caracteriza-se pela execução do trabalho em horário destinado ao descanso. Segundo Marras e Veloso (2012), um contexto com sobrecarga de pressões e excessivas demandas em curto período de tempo, pode submeter o trabalhador ao adoecimento por estresse.

O depoimento que segue exemplifica as repetidas, frequentes e volumosas demandas que recaíam sobre a entrevistada:

[...] as atividades que demandavam pra aquele setor, nunca que ia conseguir fazer considerando três pessoas. [...] A gente ficava aqui 8 horas, tem vezes que eu fico 12, 13 horas, né? [...] Eu passava, 12, 15 horas por dia trabalhando, às vezes

\section{POLÊM!CA $\mid$ LABORE}


parava para almoçar uns 10 minutos, ia buscar alguma coisa na lancheria $e$ voltava, comia no trabalho mesmo pra ir adiantando as coisas. [...] era muita cobrança externa, de pessoas que, que podiam me cobrar, ou que se sentiam, nem podiam, mas que se sentiam no direito de... de cobrar.

É importante ressaltar que, quando o sujeito é exposto a um episódio estressante por um longo período, os efeitos no organismo podem ser mais intensos, levando ao desgaste e, por vezes, ao esgotamento, comprometendo a performance do trabalhador (CAMELO, ANGERAMI, 2008).

Desta forma, nota-se que, ao tentar retratar a imagem de uma boa profissional, Camila infringia seus direitos, ultrapassando carga de tempo permitido pela organização. Além disso, com o consentimento de sua gerente, acordavam em trocar a carga maior de trabalho executado, por um "bônus”, conforme demonstrado na fala: “aí eu tinha um trato, assim, com a minha gerente, de depois tirar em dias”. Essa negociação entre a trabalhadora e a gerente aproxima-se às atuais práticas de recursos humanos cujos novos modelos, discutem CoelhoLima e Torres (2011), possuem o intuito de intensificar a exploração do trabalho e alicerçam suas ações na cooptação subjetiva dos trabalhadores, o que pode ser definido como a agregação da cognição e afeto do trabalhador na execução do seu trabalho.

Camila também faz referência a uma falha de suporte por parte de sua liderança: “[...] eu era desassistida pela minha gerente, pouco se fazia presente”. Sa e Azevedo (2010) discutem que o chefe exerce uma função psíquica potencialmente estruturante, podendo ser promissores a coesão, identificação e tratamento de conflitos. Uma liderança fragilizada ou atacada, ao que ela representa, enquanto intermediadora de ligações, de investimento psíquico e identificação, pode debilitar os vínculos entre os sujeitos na organização, favorecendo a compulsão, a repetição e a fragmentação.

O gerente, em sua função, necessita ajustar-se a possíveis mudanças, promovê-las e, ainda, trabalhar em ambientes imprevisíveis. Deixou de ser aquele que apenas dá ordens, que detém autoridade e informação - o chefe -, para atuar como intermediário nos processos, preparando e dando poder a sua equipe, partilhando informações para que os objetivos sejam alcançados (ROBBINS, 2002).

Outro fator a ser mencionado diz respeito a uma possível forma de violência no trabalho, que pode ser percebida no seguinte relato: “Eu agendava na agenda dela [gerente] reuniões, no dia da reunião ela não comparecia, eu ligava pra ela, aí ela não tava

\section{POLÊM!CA $\mid$ LABORE}


lembrando, daí ela ligava, daí ela ia pra reunião atrasada, daí na reunião ela dizia que a secretária não tinha passado a informação”.

Faria (2013) afirma que a violência no trabalho desponta onde relações de poder estão ausentes, engessadas, onde o exercício é absoluto e totalitário. Habituar-se à violência impossibilita que sua prática se rompa, por isso é de fundamental importância estar atento às formas de violência, explícitas e ocultas. Um mecanismo eficiente que oculta a violência é chamado de dissimulação discursiva, que tem como característica disfarçar as formas de violência no trabalho, mostrando-as diferentes do que são de fato, instituindo um discurso que esconde a realidade vivida.

Além do líder, a atuação da área de RH deve, ou deveria, apoiar os funcionários quanto à prevenção de possíveis estressores ocupacionais. A participante expressa: “Não, $e$ isso [avaliação do setor] nem vai acontecer porque por mais que exista interesse por parte das psicólogas do $R H$, por parte da gerência do $R H$, a gerente que ocupa a gerência daquele setor que eu trabalhava, ela tem mais poder hierárquico”.

As organizações carecem de algumas tarefas fundamentais e essenciais referentes aos recursos humanos, como as de atração, motivação e a permanência de pessoas (TANURE; EVANS; CANCADO, 2010). O objetivo principal da gestão de pessoas é o de tornar a relação entre o trabalho e o capital, em âmbito organizacional, a mais produtiva e menos conflituosa possível (ANDRADE, 2001).

Tais reflexões vão ao encontro do que compreendem Heloani e Capitão (2003), quando afirmam que o sofrimento mental do trabalhador está em grande parte atribuído à organização, isto é, à divisão do trabalho, do conteúdo da tarefa, sistema hierárquico, relações de poder, enfim, a um aparato que modela a percepção, as possibilidades de apreensão, o controle dos impulsos e a reflexão do que é produzido e também consumido nas tarefas executadas.

Além das condições da organização, estão implicadas as características individuais de Camila, que denotam significativa auto exigência, a exemplo do que retrata a fala:

E, assim, ninguém me obrigava... É, ninguém fazia plantão lá dizendo que eu tinha que ficar, mas eu sabia que a responsabilidade era minha e as atividades tinham que ser feitas. [...] Eu tenho consciência que existe, por exemplo, uma, uma...exigência minha de tá sempre tudo muito perfeito, então esse perfeccionismo, estar tudo certo, é que todos estejam bem, que todos, tudo esteja sob controle, que todas as atividades propostas estejam atendidas, né? Isso de minha parte

\section{POLÊM!CA $\mid$ LABORE}


contribuiu.

Dentre os fatores que influenciam na interação entre o trabalho e o ambiente laboral estão a satisfação no ambiente de trabalho e as condições da organização. Vinculadas a estes, estão as características individuais do trabalhador, cultura, necessidades, experiências e percepções de mundo (CAMELO, ANGERAMI, 2008). Como colocam Brant e MinayoGomez (2004), é importante distinguir que as manifestações de sofrimento não se dão de forma única para todos os sujeitos de uma mesma família, cultura ou momento histórico. Mesmo que o sujeito seja submetido às mesmas condições ambientais adversas, não necessariamente o que é sofrimento para um, será para o outro.

Ainda, os sujeitos com disposição de personalidade ao perfeccionismo têm como característica formular altos padrões de exigência atrelados a uma tendência a serem demasiadamente críticos na avaliação de seu próprio desempenho (FLETT, HEWITT, 2002). O perfeccionismo tem dois lados. O positivo é representado pelo alto rendimento e o negativo tem como característica atitudes negativas frente aos erros, dureza nas críticas pessoais e a percepção inadequada do rendimento obtido por meio das expectativas estabelecidas (STOEBER, OTTO, 2006). Portanto, tal condição pode ter contribuído para o adoecimento, que não foi sendo percebido por Camila, tampouco por colegas, gerência ou setor de Recursos Humanos da organização.

Desse modo, é explícito o que afirma Santos (2009), para quem a saúde do trabalhador não depende unicamente de sua condição como sujeito ou de condições desfavoráveis disponibilizadas pela instituição. Depende de um jogo de movimentos que acontece na relação e na forma como um e outro integram o espaço organizacional. Nesse jogo saúde-trabalho, satisfação-insatisfação e sofrimento-prazer, os sujeitos mobilizam suas inteligências e recursos disponíveis para a obtenção de soluções criativas para tornar a atividade desenvolvida possível e, também, para alcançar resultados positivos no exercício dessa atividade.

\section{Dos sintomas para a doença/diagnóstico}

As situações as quais Camila vivenciava parecem tê-la conduzido gradativamente a um esgotamento físico e mental. Ela percebia que os sintomas se manifestavam antes de seu afastamento, porém, não atribuiu importância a eles, até impossibilitar o exercício de suas

\section{POLÊM!CA $\mid$ LABORE}


atividades:

Começou com crises de choro, [...] perder o sono, é... preocupação ao extremo, falta de apetite, foram coisas que me aconteceram, ah, e eu acabei não dando bola, né? A gente, assim, não... eu acabei não prestando atenção nesse tipo de sintomas, até que teve um dia que não deu mais né?. Eu não... praticamente eu não respondia por mim mais e, eu tive que me afastar.

O que acontece com Camila instiga a refletir sobre o lugar do sofrimento no contexto do trabalho. Como argumentam Brant e Minayo-Gomez (2004), parece haver uma tendência em banir o sofrimento do meio de trabalho e desconsiderá-lo. O sofrimento, que leva ao adoecimento, tende a discriminar, estigmatizar e excluir. Além disso, quando o sofrimento é manifestado na empresa, trabalhadores e gestores não sabem como lidar com ele, ficam sem ação e referencial. Então, tudo indica que já não há lugar para as práticas de manejo do sofrimento construídas pelos próprios trabalhadores.

Além disso, parece haver uma negação ao que está ocorrendo. Depois de uma recomendação médica para que ficasse em casa, em repouso junto à família, Camila refere: “Eu tava ainda naquela pilha que eu tinha que estar no trabalho! [...] mas eu não escutei ela [médica] e eu voltei a trabalhar. Eu ainda tava naquela pilha, né? Daí eu voltei a trabalhar depois de 15 dias, e aí eu tive uma nova recaída, uma nova crise em 7 dias”.

Tal postura intensifica ainda mais o adoecimento, mas isso pode ser compreendido ao considerar o que referem Ramos, Tittoni e Nardi (2008), para quem socialmente o afastamento do trabalho relativo ao adoecimento profissional está ligado à incapacidade para o trabalho e à insegurança. A doença fica relacionada à fraqueza do trabalhador, o que faz com que esse sujeito, no aparecimento da doença, mostre-se como incapaz.

A entrevistada sugere outros aspectos, ainda, como fatores contribuintes para o seu adoecimento, como atividades acadêmicas que faziam parte do seu cotidiano:

De noite, quando eu ia pra casa assim, tipo que já era meia noite quase, 11 horas da noite, aí eu tomava banho comia alguma coisa e fazia o TCC [Trabalho de Conclusão de Curso], de madrugada. Então, claro, existe também uma contribuição da minha vida pessoal, né? Porque o TCC não é uma atividade do trabalho, mas assim, é, todo mundo faz isso, trabalha e estuda, entende, eu não podia tá tantas horas no meu trabalho. Eu ficava 6, 7 horas a mais do que eu devia.

Camila não entende as atividades acadêmicas como relacionadas ao trabalho. No entanto, como afirmam Ribeiro e Léda (2004, p. 79), “as pessoas, cada vez mais, dedicam muitas horas do seu dia às atividades profissionais, utilizam parte importante do seu tempo

\section{POLÊM!CA $\mid$ LABORE}

Polêmica - Revista Eletrônica da Uerj - Rua São Francisco Xavier, 524, $1^{\circ}$ andar

bloco D, sl.1001 • Tels.: +55 21 2334-4088/4087 • http://www.e-publicacoes.uerj.br/index.php/polemica/index http://www.labore.uerj.br • laboreuerj@yahoo.com.br 
livre se qualificando para a empregabilidade”. Desta forma, a entrevistada retrata um paradoxo que a maioria dos trabalhadores vivencia na atualidade: se, por um lado, o sujeito busca qualificação para evitar o desemprego, que pode ser considerado um agente estressor pelo fato de o trabalho ser fonte de renda e refletir sobre a autoestima e identidade social (FRANÇA; RODRIGUES, 1997), por outro, sobrecarrega o sujeito, pois as demandas excessivas e a falta de recursos para enfrentar as situações ocasionam o estresse (FRANÇA; RODRIGUES, 1997).

Conforme relato que segue, os sintomas foram se intensificando. Dos sintomas de crises de choro, perda de sono, falta de apetite, perda de energia física mencionados por Camila, ela refere o diagnóstico que recebeu:

Isso foi se arrastando meses e meses até que eu desencadeei 'Transtorno de Ansiedade Generalizada'. [...] Quando eu adoeci, foi tipo assim, óh: 6 horas da tarde eu tava muito nervosa, tava suando frio, assim, tava passando calor e eu acordei no hospital. Foi assim: daí eu fiquei 3 dias hospitalizada, daí a médica disse: aí [Camila], eu acho que vai ser bom se tu for pra casa, ficar com tua família.

O Transtorno de Ansiedade Generalizada (TAG) é caracterizado pelo excesso de preocupações relacionadas a uma variedade imensa de estímulos, somada à presença de sintomas físicos, tais como, dores pelo corpo, sudorese, palpitações, alterações dos padrões de sono, dentre outros (AMERICAN PSYCHIATRY ASSOCIATION, 2002). Embora o nexo causal não esteja evidenciado nesta situação, é apropriado advertir que as estatísticas de doenças mentais relacionadas ao trabalho crescem a cada ano, de modo que os transtornos mentais ocupam o terceiro lugar nas causas dos benefícios concedidos pela Previdência Social para doenças ocupacionais, evidenciando a relação existente entre a atividade laboral exercida e os agravos à saúde mental (AMAZARRAY, CÂMARA, CARLOTTO, 2014).

\section{$\underline{\text { Autoculpabilização }}$}

A vivência de sofrimento psíquico deve ser concebida como uma experiência individual ou coletiva de angústia, de medo e de insegurança, desenvolvida quando o trabalhador se depara com a realidade do trabalho ou quando estão presentes conflitos entre a sua busca e as restrições pelo reconhecimento do trabalho (MENDES, 2007). Quando ocorre a fragilidade do coletivo de trabalho e dos mecanismos de cooperação, pode-se dizer que há um estímulo à culpabilidade do trabalhador que adoeceu (JÚNIOR; MENDES; ARAUJO, 2009).

\section{POLÊM!CA $\mid$ LABORE}


Tais considerações podem ser claramente observadas na fala de Camila, que incita sentimentos de culpa, desamparo e insegurança:

\begin{abstract}
No início eu ficava preocupada, assim, 'o que tá acontecendo? Eu tô maluca? Eu tô louca? O que que as pessoas vão pensar de mim?' [...] Pessoas, assim, que eu tinha contato diário praticamente assim, não sabem lidar com isso, né? Então, assim, elas ficaram tão assustadas também que elas não... até hoje, assim, eu noto que elas me olham diferente.
\end{abstract}

O depoimento da entrevistada está em consonância com o que apontam alguns estudos, que demonstram que trabalhadores adoecidos, ao conviverem com situações de sofrimento resultante das mais diversas expressões do adoecimento, vivenciam situações de preconceito, sentimento de culpa, discriminação, perda de identidade, medo, dentre outros (GUIMARÃES, ALMEIDA, 2005).

Camila também demonstra culpa por não ter tomado uma atitude em seu próprio benefício: "eu também deveria ter me posicionado muitas vezes, e não fiz”. As transformações advindas do mundo do trabalho acabaram por individualizar o sujeito, fazendo com que este internalizasse a total responsabilidade pelas organizações (LINHART, 2013), como expressa Camila.

Dessa forma, Camila demonstra aflição ao perceber que não atende mais às demandas impostas a ela e experimenta o sentimento de improdutividade. Como consequência, expressa sua angústia pela ameaça de perda de identidade: “Algumas vezes ficava meio desesperada, assim, porque tipo 'que que tá acontecendo, né?, sempre fiz isso, 6 anos trabalhando manhã e tarde estudando de noite, agora eu tô fraca? Agora eu não sou ninguém?' Eu tinha préconceito comigo mesma.".

Fica evidente a autocobrança de Camila, que é reflexo de uma sociedade que valoriza a produção, ou seja, quem não produz, não tem valor, como discutem Ramos, Tittoni e Nardi (2008, p. 211): “Com relação ao afastamento do trabalho, pode-se pensar nas marcas e nos efeitos da lógica da produtividade exacerbada, designando os trabalhadores afastados como incapazes e, necessariamente, como improdutivos”.

Tal fato pode provocar a culpa que a entrevistada manifesta e que também remonta as reflexões de Gaulejac (2007) sobre a doença social. Esta, segundo o autor, caracteriza-se por paradoxos criados por esse formato de gestão e ao acobertamento da violência simbólica pelas novas regras do trabalho flexível. Os problemas sociais e os conflitos são transferidos para o

\title{
POLÊM!CA $\mid$ LABORE
}


plano individual e são tratados como distúrbios pessoais. Por outro lado, o fracasso abre uma ferida narcísica, estigmatiza o perdedor como um peso social, pois já não é permitido ser limitado. O método de quantificação da qualidade opera pela desqualificação do que é humano, pela ameaça de avaliação negativa, culpabilizando os desempregados, os precarizados e os assalariados por sua insuficiência e inaptidão para alcançar metas inacessíveis.

A entrevistada ainda refere:

Eu nunca esqueço, a primeira vez que eu fui consultar. Tava tudo errado aquele dia, sabe?! E aí, assim, pra ela [a médica] me convencer, a conseguir, a poder me internar, ela disse: Camila [nome fictício], 'tu tem mesmo que quebrar uma perna ou um braço, né? pra tu poder te internar!'. Porque eu não aceitava, sabe?

Esse depoimento revela um conteúdo próximo ao ainda preponderante paradigma clássico da medicina, que entende os processos mórbidos ocupacionais pelo viés de uma abordagem organicista (LIMA; ASSUNÇÃO; FRANCISCO, 2002), persistindo a prática de considerar os afastamentos do trabalho como uma questão da medicina geral vinculada a problemas físicos, uma vez que esses são mais palpáveis e fáceis de definir e medir do que as demandas mentais (OWENS, 1997).

O paradigma clássico da medicina, apoiado nos enunciados que são regidos a partir de uma racionalidade positiva de causa-efeito, centrada no indivíduo, também opera a lógica da culpa no trabalhador (NARDI, 1999). A atuação da psicologia no contexto laboral, que remonta a década de 20 do século passado, ainda se mantém no imaginário social e se expressa através de explicações individualizantes, que culpabilizam o trabalhador pelo acidente ou pelo adoecimento (JACQUES, 2007).

\section{$\underline{\text { Fatores contribuintes para recuperação }}$}

No momento de um adoecimento, torna-se fundamental o apoio social considerando familiares, profissionais de saúde, amigos, colegas e vizinhos no auxílio da recuperação e de enfrentamento da patologia. $\mathrm{O}$ apoio familiar varia muito de acordo com a estrutura da família e com o impacto econômico decorrente do afastamento do trabalho (TORRES, CHAGAS, MOREIRA, BARRETO, RODRIGUES, 2013). A família de Camila parece ter dado o aparato emocional que ela precisava para que conseguisse superar o adoecimento: “ [...] e eu, com ajuda da família, assim, fui me reerguendo né? Aí também depois daquele período, começou

\section{POLÊM!CA $\mid$ LABORE}


a fazer o efeito da medicação né?, que é indicada pela psiquiatra”.

Conforme Costa e Ludermir (2005), o afeto, a companhia, a assistência e a informação fazem parte do suporte emocional denominado apoio social. Ele é ofertado pela família e/ou amigos e faz com que o sujeito se sinta amado, cuidado, estimado, valorizado e seguro.

No relato supracitado, Camila também se refere ao uso de medicamento orientado pela psiquiatra como medida de recuperação de sua saúde. De acordo com Calazans e Lustoza (2008), a medicação é indicação prioritária das intervenções médico-psiquiátricas, associada a procedimentos diagnósticos descritivos, objetivados pelo discurso científico. Assim, pode-se reconhecer com evidência o paradigma do discurso médico na produção de verdade acerca do sofrimento psíquico e de sua natureza. Em atinência, Nardi (1999) coloca que tal paradigma exclui o saber dos trabalhadores.

Com relação ao apoio social, além da família, os amigos foram fundamentais no processo de recuperação de Camila: “eu tive assim amigos que nunca mais eu tinha visto e que vieram assim prestar solidariedade e dizer: 'olha, te ajuda! vamos lá, faz o tratamento certinho, nos vamos tá junto aqui!' [...] Eu tive apoio de muitos colegas meus de aula”.

Após 30 dias de afastamento do trabalho por motivo de licença saúde, a entrevistada buscou psicoterapia como forma de elaborar as questões vinculadas ao seu diagnóstico, conforme revela: “[...] daí eu comecei a terapia. [...] e hoje eu vejo, assim, que o corpo da gente, o corpo e a mente da gente é muito inteligente também, porque essa parada era necessária”.

O acompanhamento terapêutico, por constituir-se como uma forma individualizada de atendimento, permite, através do vínculo terapêutico, a elaboração de maneira mais eficaz sobre o sofrimento e a produção de relacionamentos afetivos mais significantes (FIORATI; SAEKI, 2008). É importante destacar que estratégias de intervenção centradas no indivíduo são importantes, pois aumentam e qualificam os recursos pessoais do trabalhador. No entanto, trazem limitações na medida em que podem reforçar que o adoecimento pelo trabalho é um problema do indivíduo e não da organização do trabalho.

\section{Considerações Finais}

A partir de um estudo de caso único, procurou-se investigar as possíveis relações entre o diagnóstico e as situações de trabalho de um sujeito com história de afastamento laboral por

\section{POLÊM!CA $\mid$ LABORE}


motivo de adoecimento mental. É importante refletir sobre este tema, pois ainda são insipientes as investigações que abordam o nexo causal, bem como se evidencia o desconhecimento acerca do assunto na comunidade em geral. Prova disso foi o conteúdo do relato da entrevistada, que retratou o seu próprio preconceito e de outros do seu convívio sobre as doenças mentais.

Foi possível identificar subsídios que configuram a importância do trabalho na vida de Camila tanto em âmbito de realização pessoal quanto como fonte de renda. Os possíveis fatores de adoecimento decorreram de diversos atravessamentos, como a sobrecarga de trabalho - que tende a alienar o trabalhador de forma a internalizar metas organizacionais -, e o modo de gestão que a sua gerente adotava, caracterizado como ausente e promotor de certos tipos de violência.

Além disso, a falta de apoio da empresa, neste caso representada pela área de $\mathrm{RH}$, pode ter contribuído para o seu adoecimento na medida em que não analisou o contexto do trabalho e, assim, não propiciou medidas corretivas ou preventivas de estressores. Considerando que a empresa conta com o trabalho de duas psicólogas, parece ter havido negligência, já que não foi proporcionado um espaço de escuta e um acompanhamento da situação.

O desconhecimento dos riscos ocupacionais e dos sinais e sintomas que a participante começou a vivenciar influenciaram no agravamento do quadro e progressivo adoecimento que ocasionou o seu afastamento. Neste caso, fica explícita a importância de conscientização dos trabalhadores sobre potenciais riscos de adoecimento relacionados ao trabalho, o que remete aos profissionais das diversas disciplinas, gestores públicos e pesquisadores a responsabilidade de divulgar e popularizar o conhecimento que é produzido no meio científico.

No processo de sua recuperação, diferentes formas foram salutares para que a participante retornasse ao trabalho, entre elas apoio social (família e amigos), medicamento e psicoterapia. O fato de o medicamento colocar-se como primeira alternativa de tratamento de Camila mostra como o paradigma médico ainda oprime o saber do trabalhador, incitando desafios à psicologia no que concerne a uma atuação mais efetiva.

Assim, de maneira geral, é possível constatar que as situações de trabalho, incluindo os fatores meso (institucionais) e macro (contexto social) contribuíram para o adoecimento

\section{POLÊM!CA $\mid$ LABORE}


mental de Camila, pois apresentaram condições desfavoráveis para a saúde do trabalhador. Os fatores individuais (ou micro: biografia pessoal e profissional) devem ser considerados na medida em que também influenciam o adoecimento, pois as manifestações de sofrimento não se dão de forma única para todos os sujeitos.

Esta pesquisa não pretendeu estabelecer o nexo causal entre as situações de trabalho e o adoecimento, uma vez que, para isso, é fundamental que também se descreva detalhadamente a situação de trabalho quanto ao ambiente e à organização. Por outro lado, espera-se que o resultado desta pesquisa contribua para a problematização e debate deste tema e que se amplie o conhecimento sobre o assunto. A necessidade de uma nova mentalidade, que permita a prática investigativa e compreensiva das relações entre saúde/doença e trabalho, não é exclusiva do psicólogo do trabalho, mas alusiva a todos os profissionais da saúde.

O correto diagnóstico e o estabelecimento do nexo causal são fundamentais, mas é primordial a conscientização de gestores, profissionais de RH e dos próprios trabalhadores sobre as configurações atuais do trabalho, a compreensão deste como dimensão de formação de identidade e meio de inserção social, a clareza sobre as exigências do mercado de trabalho e o reconhecimento dos riscos laborais. Desta forma, e por intermédio de uma atuação interdisciplinar, será possível que se efetivem ações resolutivas para a prevenção e o cuidado com as pessoas. Por fim, salienta-se que esta pesquisa utilizou o estudo de caso único como procedimento técnico, portanto as evidências são baseadas no relato de uma trabalhadora e não são passíveis de generalizações.

\section{Referências}

AMAZARRAY, M. R.; CÂMARA, S. G.; CARLOTTO, M. S. Investigação em saúde mental e trabalho no âmbito da saúde pública no Brasil. In: MERLO, A. R. C.; BOTTEGA, C. G.; PEREZ, K. V. (Eds.). Atenção à saúde mental do trabalhador. Porto Alegre: Evangraf, 2014.

AMERICAN PSYCHIATRIC ASSOCIATION. Manual diagnóstico e estatístico de transtornos mentais (DSM - IV-TR). 4. ed. Porto Alegre/RS: Artes Médicas, 2002.

ANDRADE, R. O. B. de. Gestão com pessoas: uma abordagem aplicada as estratégias de negócios. In: TACHIZAWA, T.; FERREIRA, V. C. P.; FORTUNA, A. A. M. Gestão com pessoas: uma abordagem aplicada as estratégias de negócios. 2. ed. Rio de Janeiro: FGV, 2001.

BARDIN, L. Análise de conteúdo. Lisboa: Edições 70, 1977.

BENDASSOLLI, P. F. Psicologia e trabalho: apropriações e significados. São Paulo: Cengage Learning, 2009.

. Crítica às apropriações psicológicas do trabalho. Psicologia \& Sociedade, v. 23, n. 1, p. 75-84, 2011.

\section{POLÊM!CA | LABORE (')}

Polêmica - Revista Eletrônica da Uerj - Rua São Francisco Xavier, 524, $1^{\circ}$ andar

bloco D, sl.1001 • Tels.: +55 21 2334-4088/4087 • http://www.e-publicacoes.uerj.br/index.php/polemica/index http://www.labore.uerj.br • laboreuerj@yahoo.com.br 
BRANT, L. C.; MINAYO-GOMEZ, C. A transformação do sofrimento em adoecimento: do nascimento da clínica à psicodinâmica do trabalho. Ciência e Saúde Coletiva, v. 9, n. 1, p. 213-223, 2004.

CAMELO, S. H. H.; ANGERAMI, E. L. S. Riscos psicossociais no trabalho que podem levar ao estresse: uma análise da literatura. Ciência, Cuidado e Saúde, v. 7, n. 2, p. 232-40, 2008.

CARLOTTO, M. S. O papel do psicólogo frente ao adoecimento e sofrimento ocupacional. Pessoas e Sintomas, v. 11, p. 49-54, 2010.

CARLOTTO, M. S.; MICHELETTO, M. R. D. Psicologia da Saúde Ocupacional. Revista Laborativa, v. 3, n. 2, p. 64-72, 2014.

CODO, W. Um diagnóstico integrado do trabalho com ênfase em Saúde Mental. In: JACQUES, M. da G. (Org). Saúde mental \& trabalho: leituras. 3. ed. Petrópolis: Vozes, 2007.

CODO, W.; SORATTO, L.; VASQUES-MENEZES, I. Saúde Mental e Trabalho. In: ZANELLI, J. C.; BORGES-ANDRADE, J. E.; BASTOS, A. V. B. (Orgs.). Psicologia, organizações e trabalho no Brasil. Porto Alegre: Artmed, 2009.

COELHO-LIMA, F.; TORRES, C. C. Reflexões sobre as políticas de gestão de recursos humanos. Caderno de Psicologia Social do Trabalho, v. 14, n. 2, p. 227-240, 2011.

COSTA, A. G. da; LUDERMIR, A. B. Transtornos mentais comuns e apoio social: estudo em comunidade rural da Zona da Mata de Pernambuco, Brasil. Caderno Saúde Pública, v. 21, n. 1, p. 73-79, 2005.

DA COSTA LEÃO, L. H.; GOMEZ, C. M. A questão da saúde mental na vigilância em saúde do trabalhador. Revista Ciência \& Saúde Coletiva, v. 19, n. 12, p. 4649-4658, 2014.

FARIA, J. H. de. Dissimulações discursivas, violência no trabalho e resistência coletiva. In: MERLO, Á. R. C.; MENDES, A. M.; MORAES, R. D. de (Orgs.). O sujeito no trabalho: entre a saúde e a patologia. Curitiba: Juruá, 2013.

FIORATI, R. C.; SAEKI, T. O acompanhamento terapêutico na internação hospitalar: inclusão social, resgate de cidadania e respeito à singularidade. Interface - Comunicação, Saúde e Educação, v. 12, n. 27, p. 763-772, 2008.

FLETT, G. L.; HEWITT, P. L. Perfectionism and maladjustment: an overview of theoretical, definitional, and treatment issues. In: FLETT, G. L.; HEWITT, P. L. (Eds.). Perfectionism: theory, research, and treatment. Washington, DC: American Psychological Association, p. 5-13, 2002.

FRANÇA, A. C. L.; RODRIGUES, A. L. Stress e trabalho: guia prático com abordagem psicossomática. São Paulo: Atlas, 1997.

GAULEJAC, V. de. Gestão como doença social: ideologia, poder gerencialista e fragmentação social. Aparecida/SP: Ideias \& Letras, 2007.

GLANZNER, C. H.; OLSCHOWSKY, A.; KANTORSKI, L. P. O trabalho como fonte de prazer: avaliação da equipe de um Centro de Atenção Psicossocial. Revista da Escola de Enfermagem da USP, v. 45, n. 3, p. 716721, 2011.

GLINA, D. M. R.; ROCHA, L. E.; BATISTA, M. L.; MENDONÇA, M. G. V. Saúde mental e trabalho: uma reflexão sobre o nexo com o trabalho e o diagnóstico, com base na prática. Caderno Saúde Pública, v. 17, n. 3, p. 607-616, 2001.

GUIMARÃES, R. F.; ALMEIDA, S. C. G. Reflexões sobre o trabalho social com famílias. In: ACOSTA, A. R.;

\section{POLÊM!CA | LABORË (3)}

Polêmica - Revista Eletrônica da Uerj - Rua São Francisco Xavier, 524, $1^{\circ}$ andar

bloco D, sl.1001 • Tels.: +55 21 2334-4088/4087 • http://www.e-publicacoes.uerj.br/index.php/polemica/index http://www.labore.uerj.br • laboreuerj@yahoo.com.br 
VITALE, M. A. F. (Org.). Família: redes, laços e políticas públicas. São Paulo: Cortez; Instituto de Estudos Especiais - PUC/SP, 2005.

HELOANI, J. R.; CAPITÃO, C. G. Saúde mental e psicologia do trabalho. São Paulo em Perspectiva, v. 17, n. 2, p. 102-108, 2003.

JACQUES, M. da G. O nexo causal em saúde/doença mental no trabalho: uma demanda para a psicologia. Psicologia \& Sociedade, v. 19, n. especial, p. 112-119, 2007.

LACAZ, F. A. de C. O campo saúde do trabalhador: resgatando conhecimentos e práticas sobre as relações trabalho-saúde. Caderno Saúde Pública, v. 23, n. 4, p. 757-766, 2007.

LANCMAN, S. O mundo do trabalho e a psicodinâmica do trabalho. In: LANCMAN, S.; SZNELWAR, L. I. (Org.). Christophe Dejours: da psicopatologia à psicodinâmica do trabalho. Rio de Janeiro: Fiocruz, 2008.

LEÃO, L. H. D. C. Psicologia do Trabalho: aspectos históricos, abordagens e desafios atuais. ECOS-Estudos Contemporâneos da Subjetividade, v. 2, n. 2, p. 291-305, 2012.

LIMA, M. E. A. Transtornos mentais e trabalho: o problema do nexo causal. Revista de Administração, v. 2, n. 1, jun. 2005.

. Os problemas de saúde na categoria bancária: considerações acerca do estabelecimento do nexo causal. Boletim da Saúde, v. 1, n. p. 57-68, 2006.

LIMA, M. E. A; ASSUNÇÃO, A. A.; FRANCISCO, J. M. S. D. Aprisionado pelos ponteiros de um relógio: o caso de um transtorno mental desencadeado no trabalho. In: JACQUES, M. G.; CODO, W. (Orgs.). Saúde Mental \& Trabalho. Petrópolis, Rio de Janeiro: Editora Vozes, 2002.

LINHART, D. O indivíduo no centro da modernização das empresas: um reconhecimento esperado, mas perigoso. Trabalho \& Educação, v. 7, p. 24-36, 2013.

MARRAS, J. P.; VELOSO, H. M. Estresse ocupacional. Rio de Janeiro: Elsevier, 2012.

MENDES, A. (Org.). Psicodinâmica do trabalho: teoria, método e pesquisas. São Paulo: Casa do Psicólogo, 2007.

MENEZES DE CARVALHO, G.; DUTRA DE MORAES, R. Sobrecarga de trabalho e adoecimento no Polo Industrial de Manaus. Psicologia em Revista, v. 17, n. 3, p. 465-482, 2011.

MENEZES-VASQUES, I. Saúde do trabalhador: uma breve sistematização. In: FERREIRA, M. C. L.; MENDONÇA, H. (Orgs.). Saúde e bem-estar no trabalho: dimensões individuais e culturais. São Paulo: Casa do Psicólogo, 2012.

MINAYO, M. C. S. O desafio do conhecimento: pesquisa qualitativa em saúde. 10. ed. São Paulo: Hucitec, 2007.

MINAYO-GOMEZ, C.; THEDIM-COSTA, S. M. da F. A construção do campo da saúde do trabalhador: percurso e dilemas. Caderno Saúde Pública, v.13, n.2, p. 21-32, 1997.

MINISTÉRIO DA PREVIDÊNCIA E ASSISTÊNCIA SOCIAL. Medida Provisória no 316 de 11 de agosto de 2006. Disponível em http://www.camara.leg.br/sileg/integras/414866.pdf. Acesso em 26 mar. 2016.

MINISTÉRIO DA SAÚDE. 3. ${ }^{\text {a }}$ Conferência Nacional de Saúde do Trabalhador: $3 .{ }^{\text {a }}$ CNST: "trabalhar, sim! adoecer, não!”: coletânea de textos. Brasília: Ministério da Saúde, 2005.

. Lei Orgânica da Saúde no 8.010, 1990. Disponível em:

\section{POLÊM!CA | LABORE (3)}

Polêmica - Revista Eletrônica da Uerj - Rua São Francisco Xavier, 524, $1^{\circ}$ andar

bloco D, sl.1001 • Tels.: +55 21 2334-4088/4087 • http://www.e-publicacoes.uerj.br/index.php/polemica/index http://www.labore.uerj.br • laboreuerj@yahoo.com.br 
<http://www.planalto.gov.br/ccivil_03/leis/18080.htm>. Acesso em: 01 nov. 2014.

MOURA NETO, F. D. M. de. Experiências de organização de referência para o diagnóstico e investigação da relação causal entre o trabalho e agravos à saúde mental. In: MERLO, A. R. C.; BOTTEGA, C. G.; PEREZ, K. V. (Eds.). Atenção à saúde mental do trabalhador. Porto Alegre: Evangraf, 2014.

NARDI, H. C. Saúde, trabalho e discurso médico: a relação médico-paciente e o conflito capital-trabalho. São Leopoldo: Editora Unisinos, 1999.

Saúde do Trabalhador. In: CATTANI, Antonio David (Org.). Trabalho e tecnologia: dicionário crítico. 3. ed. Petrópolis: Vozes, 2000.

NAVARRO, V. L.; PADILHA, V. Dilemas do trabalho no capitalismo contemporâneo. Psicologia \& Sociedade, v. 19, n. especial, p. 14-20, 2007.

OWENS, P. Mental Health: understanding work disability issue. Health Insurense Underwriter, jan, p. 1-4, 1997.

RAMOS, M. Z.; TITTONI, J.; NARDI, H. C. A experiência de afastamento do trabalho por adoecimento vivenciada como processo de ruptura ou continuidade nos modos de viver. Cadernos de Psicologia Social e do Trabalho, v. 11, n. 2, p. 209-221, 2008.

RIBEIRO, C. V. S.; LÉDA, D. B. O significado do trabalho em tempos de reestruturação produtiva. Estudos e Pesquisas em Psicologia, v. 4, n. 2, p. 76-83, 2004.

ROBBINS, S. P. Administração: mudanças e perspectivas. São Paulo: Saraiva, 2002.

SA, M. de C.; AZEVEDO, C. S. Subjetividade e gestão: explorando as articulações psicossociais no trabalho gerencial e no trabalho em saúde. Ciência e Saúde Coletiva, v. 15, n. 5, p. 2345-2354, 2010.

SALANOVA, M.; SCHAUFELI, W. B. El engagement en el trabajo. Madrid: Alianza Editorial, 2009.

SANTOS, G. B. dos. Os professores e seus mecanismos de fuga e enfrentamento. Trabalho, Educação e Saúde, v. 7, n. 2, p. 285-304, 2009.

SATO, L.; LACAZ, F. A. de C.; BERNARDO, M. H. Psicologia e saúde do trabalhador: práticas e investigações na Saúde Pública de São Paulo. Estudos de Psicologia, v. 11, n. 3, p. 281-288, 2006.

STOEBER, J.; OTTO, K. Positive conceptions of perfectionism: approaches, evidence, challenges. Personality and Social Psychology Review, v. 10, p. 295-319, 2006.

TANURE, B.; EVANS, P.; CANCADO, V. L. As quatro faces de RH: analisando a performance da gestão de Recursos Humanos em empresas no Brasil. Revista de Administração Contemporânea, v. 14, n. 4, p. 594-614, 2010.

TODESCHINI, R; LINO, D. A importância social do Ntep e a busca de integração das políticas públicas de segurança e saúde do trabalhador. In: MACHADO, Jorge; SORATTO, Lúcia; CODO, Wanderley (Orgs.). Saúde e trabalho no Brasil: uma revolução silenciosa. O Ntep e a previdência social. Petrópolis: Vozes, 2010.

TOMASI, N. G. S.; YAMAMOTO, R. M. Metodologia da pesquisa em saúde: fundamentos essenciais. Curitiba: As autoras, 1999.

TORRES, A. R. A.; CHAGAS, M. I. O., MOREIRA, A. C. A.; BARRETO, I. C. D. H. C.; RODRIGUES, E. M. O adoecimento no trabalho: repercussões na vida do trabalhador e de sua família. SANARE-Rev. Políticas

Públicas, v. 10, n. 1, 2013.

\section{POLÊM!CA $\mid$ LABORE (E)}

Polêmica - Revista Eletrônica da Uerj - Rua São Francisco Xavier, 524, $1^{\circ}$ andar

bloco D, sl.1001 • Tels.: +55 21 2334-4088/4087 • http://www.e-publicacoes.uerj.br/index.php/polemica/index

http://www.labore.uerj.br • laboreuerj@yahoo.com.br 
TURATO, E. R. Métodos qualitativos e quantitativos na área da saúde: definições, diferenças e seus objetos de pesquisa. Rev. Saúde Pública, v. 39, n. 3, p. 507-14, 2005.

YIN, R. K. Estudo de Caso: planejamento e métodos. São Paulo: Bookman, 2015.

Recebido em: 25/01/2016.

Aceito em: 05/04/2016.

\section{POLÊM!CA $\mid$ LABORE}

Polêmica - Revista Eletrônica da Uerj - Rua São Francisco Xavier, 524, $1^{\circ}$ andar bloco D, sl.1001 • Tels.: +55 21 2334-4088/4087 • http://www.e-publicacoes.uerj.br/index.php/polemica/index http://www.labore.uerj.br • laboreuerj@yahoo.com.br 